\title{
Equity on Health Services Access of People with Common Mental Disorders in Sao Paulo City
}

\author{
Venancio dos Santos GDB1,5*, Porto Alves MCG², Goldbaum M³3, \\ Galvao Cesar $\mathrm{CL}^{4}$ and Jose Gianini $\mathrm{R}^{1}$ \\ 1Medical and Health Sciences School-PUCSP, Brazil \\ 2Institute of Health. São Paulo State Department of Health, Brazil \\ ${ }^{3}$ Department of Preventive Medicine University of São Paulo, Medicine School, \\ Brazil \\ ${ }^{4}$ Department of Epidemiology, University of São Paulo. Public Health School, Brazil \\ ${ }^{5}$ Scholarship of scientific initiation - CNPq
}

\begin{tabular}{|c|}
\hline Research Article \\
Volume 3 Issue 1 \\
Received Date: February 27, 2019 \\
Published Date: April 09, 2019 \\
D0I: $10.23880 /$ eij-16000119 \\
\hline
\end{tabular}

*Corresponding author: Gustavo de Brito Venancio dos Santos, Medical and Health Sciences School, Brazil, Tel: 15997852888; Email: venanciogustavodebrito@hotmail.com

\section{Abstract}

Background: Reducing deaths of newborn and children under 5 years of age became an agenda. The effect of preceding birth interval on child mortality was evidenced by different findings. The objective of this study was assessing the effects of preceding birth interval on child mortality in Ethiopia.

Methods: The study participants were 8460 non-first births in the 5 years before the 2016 EDHS (Ethiopian demographic health survey). Data analysis was done by using SPSS version 20. Bivariate and multivariate logistic regression analysis was done to assess the relationship between dependent and independent variables. Odds ratio at $95 \%$ CI was computed to assess the strength of association between dependent and independent variables. Variables with P-value $<0.05$ in multivariate analysis was used to declare significance of association.

Result: Child whose proceeding birth interval was less than 18 months (AOR= 2.769; CI 95 \%( 1.956, 3.921)) and child whose preceding birth interval was between 18 and 23 months (AOR=1.500; 95 \% CI $(1.038,2.168)$ ) were more likely to die than child with birth interval of 60 months and above. Child whose preceding birth interval was between 36 and 47 months $(\mathrm{AOR}=0.663,95 \% \mathrm{CI}(.446, .986))$ was less likely to die than child with birth interval of 60 months and above.

Conclusion: The preceding birth interval and child mortality was significantly associated. Child whose preceding birth interval less than 18 months, and 18 to 23 months were more likely to die than child with birth interval of 60 months and above. Child whose preceding birth interval was between 36 and 47 months was less likely than to die than child with birth interval of 60 months. Health education on effect of short preceding birth interval should be given by health workers. Promotion of family planning should be strengthened at all levels.

Keywords: Health Services Access; Health Equity; Mental Health; Health surveys 


\section{Epidemiology international journal}

\section{Introduction}

Mental illness is present worldwide and generates a huge social and economic impact. A new estimation attributed $32.4 \%$ of years lived with disability and $13.0 \%$ of disability-adjusted life-years to the global burden of mental illness [1]. Developing countries face a high prevalence of these diseases and are not well prepared to handle them [2]. Furthermore, an association between poverty and mental health diseases in these nations has been suggested [3].

Goldberg and Huxley introduced the term Common Mental Disorders (CMD) to describe a set of somatic, depressive and anxiety symptoms that causes important mental impairment [4]. Researches and practitioners have been accessed it through the selfreporting questionnaire (SRQ-20), which is a screening tool for mental disorders recommended by the world health organization to be used in the primary care system of developing countries [5].

In Brazil, estimations of the prevalence of common mental disorders vary from $17 \%$ to $35 \%$ [6-11]. The importance of these studies resides on the direction for public health polices and the recognition of possible risk factors and vulnerable populations.

The vulnerability patterns and the social determinants are paramount to achieve health equity, mainly in mental health [12]. Consequently, the population who needs more assistance for facing social and health inequalities can be prioritized. One way to guarantee this condition is through health services access. Given these circumstances, the aim of this research was to investigate the health services access of people with common mental disorders who lived in São Paulo city urban area in the year of 2015.

\section{Methods}

The analysis was made through the data from São Paulo city Inquiry ISA-Capital 2015 [13]. It is the third edition of a survey population-based inquiry that took place in 2015. The participants were residents from the urban area of São Paulo city. Clusters stratified the probabilistic sample in two stages: census tracts (4 groups) and households (5 groups). The regional health offices (North, Midwest, southeast, south and east) were used to stratified the county. 30 census sectors were raffled in each office based on the urban sectors of the 2010 demographic census. The ISA-Capital 2015 sample was formed by the following domains: 12-19 years (males and females), 20 -59 years (male), 20-59 years (female) and $\geq 60$ years (male and female). It was calculated based on an estimate of prevalence of $50 \%$, with 0.10 of sample error considering a level of $95 \%$ of confidence and an effect design of 1.5 .
In this research the individuals selected were all of those who answered the block $\mathrm{E}$ on the populationbased inquiry and were 15 years old or older. A total of 3619 people.

The Common mental disorder was assessed by the self-reporting questionnaire (SRQ-20), which contains 20 simple yes or no questions and corresponds the block E on ISA-Capital 2015. This questionnaire was validated in Brazil in 1986 by Mari and Williams [14] in a study that compared it to the standardized psychiatric interview. The sensitivity, taking into consideration the cutting-point of $5 / 6$ for men and $7 / 8$ for women, was $83 \%$ and specificity $80 \%$, being a good indicator of morbidity. A more recent validation research conducted in 2008 by Gonçalves, Stein and Kapczinski [15] showed a sensitivity of $86.33 \%$ and specificity of $89.31 \%$, considering the cutting-point of $7 / 8$ (compared to the structured clinical interview for DSM-IV-TR as gold standard). The discriminatory power was 0.91 and the Cronbach's alpha 0.86. Moreover, Scafuza, et al. in 2009 [16] tested the SRQ-20 validity in the elderly population finding the cutting-point $4 / 5$ with the best sensitivity and specificity for both genders. Therefore, in this research, the cutting points to establish the presence of CMD were: 64 years old or younger men - 6 or more positive answers; 64 years old or younger women - 8 or more positive answers [14] and 65-year-old or older men or women - 5 or more positive answers [16].

The socio-demographic variables were: sex; age group; skin color; religion; marital status; education; working status; and Income. The health condition variables were: morbidity referred in the last 15 days; physical disability; mental/intellectual disability; chronic disease; and headache. The variables related with the health services access were: seek for healthcare assistance in the last 30 days and availability of healthcare services. Furthermore, the dependent variable was the presence or absence of CMD. Initially, a frequency distribution of the health services access variables among the positive and negative CMD screening groups was made. The statistical significance of the prevalence ratio in each observation was evaluated through Chi-square test corrected by the Satterthwaite's approximate F test. Secondly, an univariate analysis was conducted to verify the association between the socio-demographic/health condition variables and the health services access variables in both holders an non-holders of CDM. Additionally, we used multivariate analysis through Poisson regression. In the initial model all variable/categories were included and analyzed by the stepwise backward process. At the end only the variables with $\mathrm{p}<0.05$ remained in the final model.

The analysis took into consideration the stratification, wheighted and cluster sampling process. 


\section{Epidemiology international journal}

The software STATA 11 did all the statistical analysis. The ethics committee of PUC-SP, Sorocaba Campus, approved this research (CAAE 66296917.0.0000.5373).

\section{Results}

Among the 3619 individuals of the sample, 780 had a positive screening for CMD. Thus, the prevalence of CMD, considering the sample weights, was $19,7 \%$
(IC95\%:18.2 - 21.4\%).

Analysing the variables related with the health services access (Table 1) a higher prevalence of CMD was found in those who seek for healthcare assistance in the last 30 days (25.4\%). There was no difference of revalence between those who found lack of availability of healthcare services and those who found healthcare services available in the last seek for service.

\begin{tabular}{|c|c|c|c|c|c|c|}
\hline Variable & $\begin{array}{l}\text { n\% without } \\
\text { CMD }\end{array}$ & n\% with & $\begin{array}{c}\text { Corrected } \\
\text { Prevalence of } \\
\text { CMD }\end{array}$ & $\begin{array}{l}\text { Prevalence } \\
\text { Ratio }\end{array}$ & $\begin{array}{c}\text { Confidence } \\
\text { Interval }\end{array}$ & $\mathbf{p}$ \\
\hline Seek for healthcare assistance & & & & & & $<0.001$ \\
\hline Until 1month & $\begin{array}{c}829 \\
71.60 \% \\
\end{array}$ & $\begin{array}{c}329 \\
28.40 \% \\
\end{array}$ & $25.40 \%$ & 1.49 & $1.29-1.71$ & $<0.001$ \\
\hline More than 1 month & $\begin{array}{c}1996 \\
81.74 \% \\
\end{array}$ & $\begin{array}{c}446 \\
18.26 \% \\
\end{array}$ & $17.10 \%$ & 1 & & \\
\hline $\begin{array}{c}\text { Availability of healthcare } \\
\text { services }\end{array}$ & & & & & & 0.22 \\
\hline $\begin{array}{c}\text { Lack of availability of healthcare } \\
\text { services (in the last seek for } \\
\text { service) }\end{array}$ & $\begin{array}{c}115 \\
82.10 \%\end{array}$ & $\begin{array}{c}25 \\
17.90 \%\end{array}$ & $15.40 \%$ & 1 & & \\
\hline $\begin{array}{l}\text { healthcare services were available } \\
\text { (in the last seek for service) }\end{array}$ & $\begin{array}{c}2718 \\
78.30 \% \\
\end{array}$ & $\begin{array}{c}755 \\
21.70 \% \\
\end{array}$ & $20 \%$ & 1.29 & $0.84-2.00$ & 0.234 \\
\hline
\end{tabular}

Table 1: CMD Prevalence and prevalence ratio in accordance with the health services access variables.

In the univariate analysis of the frequency distribution of the fixed variable "seek for healthcare assistance until 1 month" (Table 2) we found a significant association among the people with a positive
CDM screening in the following factor variables: sex; age group; skin color; marital status; working status; morbidity referred in the last 15 days; physical disability; and chronic disease.

\begin{tabular}{|c|c|c|c|c|c|}
\hline \multirow{2}{*}{$\begin{array}{c}\text { Fixed Variable } \\
\begin{array}{c}\text { Seek for healthcare assistance } \\
\text { until } 1 \text { month }\end{array}\end{array}$} & \multirow[t]{2}{*}{ Factor Variable } & \multicolumn{4}{|c|}{ Positive CMD screening } \\
\hline & & $\%$ & Prevalence Ratio & $\mathrm{p}$ & $95 \%$ CI \\
\hline & Sex & & & $<0.001$ & \\
\hline & Male & 30.1 & 1 & & \\
\hline & Female & 46.4 & 1.13 & $<0.001$ & $1.05-1.2$ \\
\hline & Age group & & & 0.016 & \\
\hline & $15 / 29$ & 31.2 & 1 & & \\
\hline & $30 / 44$ & 44.7 & 1.1 & 0.027 & $1.01-1.20$ \\
\hline & $45 / 59$ & 40.6 & 1.07 & 0.106 & $0.98-1.16$ \\
\hline & 60 or more & 48.6 & 1.13 & 0.001 & $1.05-1.22$ \\
\hline & Skin color & & & 0.043 & \\
\hline & White & 46 & 1 & & \\
\hline & Black & 35.6 & 0.93 & 0.143 & $0.84-1.03$ \\
\hline & Yellow or indigenous & 43.8 & 0.98 & 0.892 & $0.79-1.23$ \\
\hline & Brown & 33.8 & 0.92 & 0.007 & $0.86-0.97$ \\
\hline & Religion & & & 0.918 & \\
\hline & Catholic & 42.7 & 1 & & \\
\hline & Evangelical/Protestant & 40.1 & 0.98 & 0.602 & $0.92-1.05$ \\
\hline & None & 37.5 & 0.96 & 0.437 & $0.88-1.06$ \\
\hline & Spiritism or Buddhism & 44.8 & 1.01 & 0.793 & $0.91-113$ \\
\hline & Judaism & 44.8 & 1.01 & 0.193 & $0.91-1.13$ \\
\hline & Umbanda/Candomblé & 39 & 0.97 & 0.827 & $0.77-1.23$ \\
\hline & Marital Status & & & 0.047 & \\
\hline
\end{tabular}




\section{Epidemiology international journal}

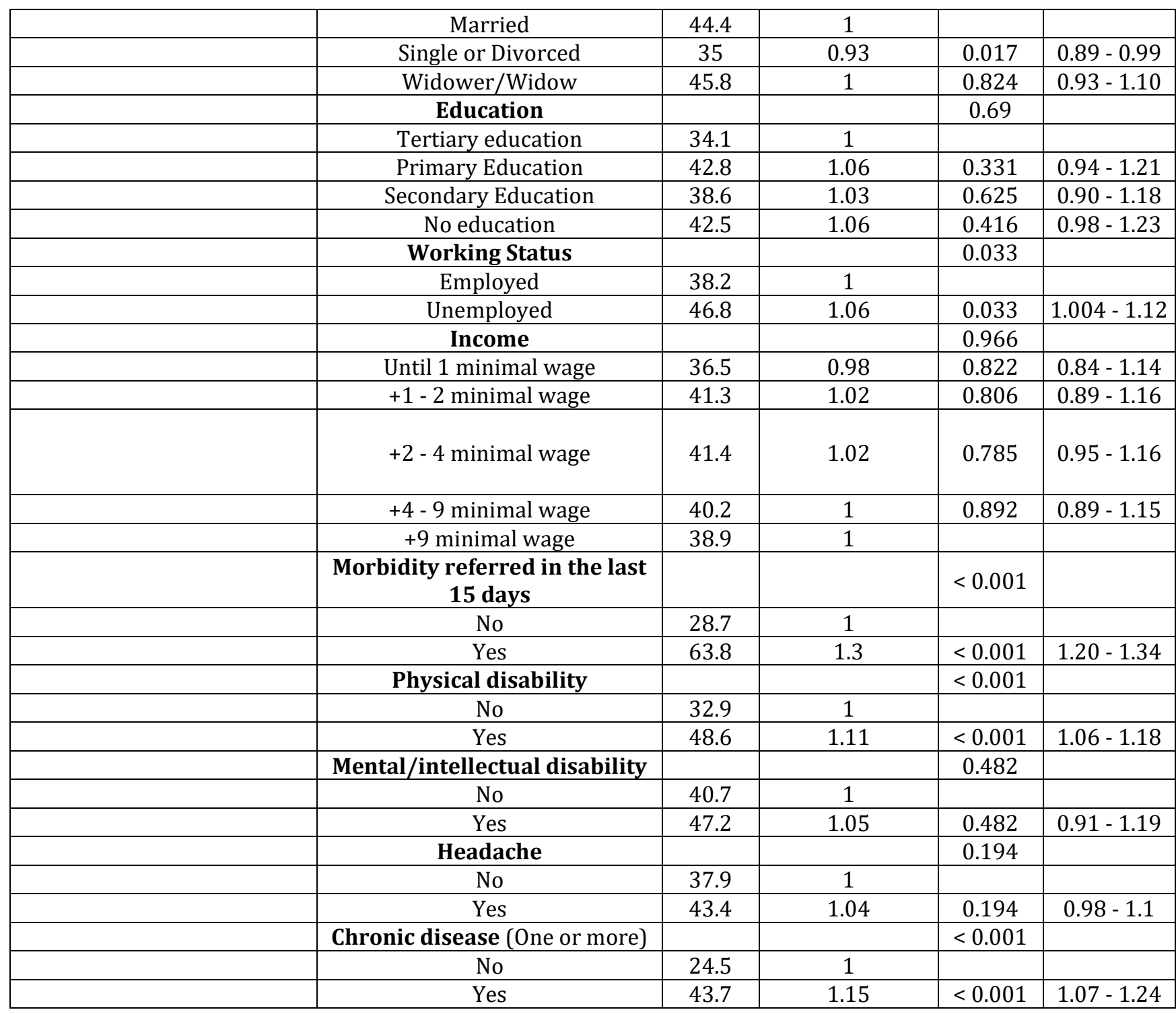

Table 2: Frequency distribution of the fixed variable "seek for healthcare assistance until 1 month" in accordance with the factor variables for positive CMD screening groups.

In the multivariate analysis of the fixed variable "seek for healthcare assistance until 1 month" (Table 3) the factor variables which remained in the final model having an independent effect among the positive CMD screening group were: sex; skin color; marital status; morbidity referred in the last 15 days; physical disability; and chronic disease.

\begin{tabular}{|c|c|c|c|c|}
\hline Variable & Category & \multicolumn{3}{|c|}{ Positive CMD screening } \\
\hline \multirow{3}{*}{ Sex } & & PR & 95\% CI & \\
\hline \multirow{3}{*}{ Skin Color } & Male & 1 & $1.05-1.2$ & $<0.001$ \\
\cline { 2 - 5 } & Female & 1.12 & $0.86-1.06$ \\
\cline { 2 - 5 } & White & 1 & 0.392 \\
\cline { 2 - 5 } & Black & 0.96 & $0.79-1.19$ & 0.755 \\
\cline { 2 - 5 } & Yellow or indigenous & 0.97 & $0.87-0.99$ & 0.113 \\
\cline { 2 - 5 } & Brown & 0.93 & $0.89-1.01$ & 0.025 \\
\hline
\end{tabular}




\section{Epidemiology international journal}

\begin{tabular}{|c|c|c|c|c|}
\hline $\begin{array}{c}\text { Morbidity referred in } \\
\text { the last 15 days }\end{array}$ & Yes & 1.25 & $1.18-1.32$ & $<0.001$ \\
\hline Physical disability & Yes & 1.1 & $1.18-1.32$ & 0.001 \\
\hline $\begin{array}{c}\text { Chronic disease (One or } \\
\text { more) }\end{array}$ & Yes & 1.08 & $1.01-1.16$ & 0.04 \\
\hline
\end{tabular}

Table 3: Multivariate analysis (Poisson regression) - Variable seek for healthcare assistance until 1 month in accordance with the sociodemographic and health condition variables.

In the univariate analysis of the frequency distribution of the fixed variable "healthcare services were available in the last seek for service", the variables with statistical association in the positive CMD screening group were education and income. However, in the multivariate analysis none of these factor variables remained in the final model having an independent effect.

\section{Discussion}

The prevalence of CMD in this study was $19.7 \%$ (95\%CI: 18.2 - 21.4\%). In the systematic review with meta-analysis made by Steel, et al. in 2014 [17] a global prevalence estimation of CMD was 17.6\% (95\%CI:16.3$18.9 \%$ ). As the intervals of confidence overlap, we can assume the similarity with the current literature. Those who sought for healthcare assistance in the last 30 days (28.4\%) had a prevalence ratio of CMD of 1.49 (95\%CI: 1.29 - 1.71). In the univariate analysis, sex; age group; skin color; marital status; working status; morbidity referred in the last 15 days; physical disability; and chronic disease were the variables associated with the fixed variable "seek for healthcare assistance until 1 month" in the positive screening CDM group. However only the variables sex; skin color; marital status; morbidity referred in the last 15 days; physical disability; and chronic disease remained in the multivariate analysis with significant statistical difference.

The higher prevalence of CMD in those who sought health care assistance in the last 30 days highlighted a specific demand and an opportunity to improve the diagnosis and treatment of these patients. Golçalves e Kapczinski [18] in 2008 found that 51.1\% of the individuals who sought health services in the primary care unity of Santa Cruz do Sul in Rio Grande do Sul were diagnosed with some psychiatric disorder. Moreover, these patients had more visits to health services in the last 12 months. Despite of the lack of sample variability in this study, which limits the generalization process, is possible to recognize a similar pattern comparing the researches. And it seems to occur mainly on the primary health care services.

The difference between men and women about careseeking behavior shows a common trend. Women with CMD had a 1.12 more prevalence of the variable seeking healthcare assistance in the last month (95\%CI 1.05 1.2) when compared with men with CMD. A study conducted in Canada and published in 2016 [19] demonstrated a gender difference in the seeking out healthcare, where women reported visiting their primary care provider more frequently than men, both for physical and mental health problems. In Brazil, Pinheiro, et al. [20] point out that women refer more morbidity and psychological problems than men and, consequentially, look more for medical services. In other Brazilian study published in 2014 that analyzed the gender difference in the care-seeking behavior [21], other factors were associated with the non-demand for health services like time of opening of health care facilities and working hours of the user.

In United States of America, race and ethnic minorities, like Latinos, blacks and native Americans, have less access to healthcare services when compared to whites [22]. In Brazil, the results of a national health survey made in 2013 [23] found that white people reported less underutilization of healthcare than nowhite individuals. In our research, neither black, yellow or indigenous individuals showed a statistical difference in the correlation with the variable "seek for healthcare assistance until 1 month" when compared to white individuals. However, brown individuals had a prevalence ratio 0.93 (95\%CI 0.87 - 0.99) of this variable when compared with white people.

Widowers and widows with CMD had a slightly lower seeking behavior when compared to married individuals (PR 0.99 95\%CI 0.82 - 0.99), which can be a specificity of mental health patients with this marital status, once other studies demonstrated the opposite for general widowers/widows [24,25]. As expected, people with health conditions like morbidity referred in the last 15 days and chronic diseases sought more for medical assistance. Faithfully, there was no difference in the prevalence of CMD considering the availability of healthcare services. Moreover, in the multivariate analysis none factor variable presented an independent effect with the variable "healthcare services were available in the last seek for service", which reflects an egalitarian access. However, only one aspect of access, the availability of healthcare services, was measured. There are many dimensions when considering access including factors as individual-level, practitioner-level, 
system- and process-level, and resource-based or practical level [26].

\section{Conclusion}

Given the results, it is possible to identify vulnerable groups and in this way direct proper attention and further research. People who recently sought medical assistance had a higher prevalence of common mental disorders, which can serve as an alert for health practitioners. Furthermore, among people with a positive CMD screening some socioeconomic variables categories (women, brown individuals and widowers/widows) were associated with a higher seeking healthcare behavior. This is important to understand the specific context of this population and create polices to convey healthcare taking into consideration the principle of equity. Regarding the availability of healthcare services, one indirect measure of health access, people with CMD did not receive a different treatment when compared with the negative CMD screening group, which is favourable, although other aspects of health services access should be investigated in further research. Despite of the fact that the sample was representative of population and the data were collected by training staff, the research is based on self-referred information, which can be listed as a study limitation. Moreover, the study design does not allow to establish a causality effect or to test this hypothesis. Finally, the seeking behaviour for healthcare facilities is influenced by others factors besides the socio-demographic variables analysed. There are individual factors (E.g. recognize the need to seek healthcare and have the knowledge about the available facilities) and external factors (E.g. transport, the distance until the healthcare service and communication) that should be considerate.

Conflicts of Interest: The Authors declare to have no conflict of interest.

\section{Funding}

One of the authors received a scholarship from the $\mathrm{CNPq}$ to do this research as part of the scientific initiation Scholarship Proagram (PIBIC).

\section{References}

1. Vigo D, Thornicroft G, Atun R (2016) Estimating the true global burden of mental illness. Lancet Psychiatry 3(2): 171-178.

2. Patel V (2007) Mental health in low- and middleincome countries. Br Med Bull 81(82): 81-96.
3. Patel V, Kleinman A (2003) Poverty and common mental disorders in developing countries. Bull World Health Organ 81(8): 609-615.

4. Goldberg DP, Huxley P (1992) Common mental disorders: A bio-social model. Common mental disorders: A bio-social model, Newyork, US, pp: 194.

5. World Health Organization: Division of Mental Health (1994) A User's guide to the self-reporting questionnaire (SRQ). World Health Organization, Geneva.

6. Ludermir AB, Melo Filho DA (2002) Condições de vida e estrutura ocupacional associadas a transtornos mentais comuns. Rev Saúde Pública 36(2): 213-221.

7. Mendoza-Sassi RA, Béria JU (2007) Gender differences in self-reported morbidity: evidence from a population-based study in southern Brazil. Cad Saúde Pública 23(2): 341-346.

8. Marín-León L, Oliveira HB, Barros MBA, Dalgalarrondo P, Botega NJ (2007) Social inequality and common mental disorders. Rev Bras Psiquiatr 29(3): 250-253.

9. Rocha SV, Almeida MMG, Araújo TM, Virtuoso Júnior JS (2010) Prevalência de transtornos mentais comuns entre residentes em áreas urbanas de Feira de Santana, Bahia. Rev Bras Epidemiol 13(4): 630-640.

10. Rodrigues-Neto JF, Figueiredo MFS, Faria AAS, Fagundes M (2008) Transtornos mentais comuns e o uso de práticas de medicina complementar e alternativa: estudo de base populacional. J Bras Psiquiatr 57(4): 233-239.

11. Moraes Júnior EC (2010) Prevalência e fatores de risco para transtorno mental comum na população urbana da região metropolitana de Sâo Paulo. dissertação, Universidade Estadual "Júlio de Mesquita Filho". Faculdade de Medicina.

12. Satcher D, Rachel SA (2017) Promoting mental health equity: the role of integrated care. J Clin Psychol Med Settings 24(3-4): 182-186.

13. Alves MCGP, Escuder MML, Goldbaum M, Barros MB de A, Fisberg RM, et al. (2018) Sampling plan in health surveys, city of São Paulo, Brazil, 2015. Rev Saúde Pública 52: 81.

14. Mari JJ, Williams $P$ (1986) A validity study of a psychiatric screening questionnaire (SRQ-20) in primary care in the city of Sao Paulo. Br J Psychiatry 148: $23-26$. 


\section{Epidemiology international journal}

15. Gonçalves DM, Stein AT, Kapczinski F (2008) Avaliação de desempenho do Self-Reporting Questionnaire como instrumento de rastreamento psiquiátrico: um estudo comparativo com o Structured Clinical Interview for DSM-IV-TR. Cad Saúde Pública 24(2): 380-390.

16. Scazufca M, Menezes PR, Vallada H, Araya R (2009) Validity of the self-reporting questionnaire-20 in epidemiological studies with older adults. results from the Sao Paulo Ageing \& Health Study. Soc Psychiatry Psychiatr Epidemiol 44(3): 247-254.

17. Steel Z, Marnane C, Iranpour C, Chey T, Jackson JW, et al. (2014) The global prevalence of common mental disorders: a systematic review and metaanalysis 1980-2013. Int J Epidemiol 43(2): 476493.

18. Gonçalves DM, Kapczinski F (2008) Prevalência de transtornos mentais em indivíduos de uma unidade de referência para Programa Saúde da Família em Santa Cruz do Sul, Rio Grande do Sul, Brasil. Cad Saúde Pública 24(9): 2043-2053.

19. Thompson AE, Anisimowicz Y, Miedema B, Hogg W, Wodchis WP, et al. (2016) The influence of gender and other patient characteristics on health careseeking behaviour: a QUALICOPC study. BMC Fam Pract 17: 38.
20. Pinheiro RS, Viacava F, Travassos C, Brito A, dos S (2002) Gênero, morbidade, acesso e utilização de serviços de saúde no Brasil. Ciênc Saúde Coletiva 7: 687-707.

21. Levorato CD, Mello LM de, Silva AS da, Nunes AA (2014) Fatores associados à procura por serviços de saúde numa perspectiva relacional de gênero. Ciênc Saúde Coletiva 19(4): 1263-1274.

22. Smedley BD, Stith AY, Nelson AR (2003) Unequal Treatment: Confronting Racial and Ethnic Disparities in Health Care.

23. Boccolini CS, de Souza Junior PRB (2016) Inequities in Healthcare utilization: results of the Brazilian National Health Survey, 2013. Int J Equity Health 15: 150 .

24. Arruda GO de, Mathias TA de F, Marcon SS (2017) Prevalência e fatores associados à utilização de serviços públicos de saúde por homens adultos. Ciênc Saúde Coletiva 22(1): 279-290.

25. Joung IM, van der Meer JB, Mackenbach JP (1995) Marital status and health care utilization. Int J Epidemiol 24(3): 569-575.

26. National Collaborating Centre for Mental Health (UK) (2011) Common Mental Health Disorders: Identification and Pathways to Care. Leicester (UK). 